\title{
DA ESTÉTICA À (EST)ÉTICA
}

Rafael Andrés Villari *

RESUMO: O texto visa - partindo da chivida de Sigmund Freud sobre a verdadeira origem de William Shakespeare e da formulação do crítico norte-americano Harold Bloom sobre a angústia de influência - assinalar a distinção existente entre o efeito estético e a conseqüência ética das formações do inconsciente freudiano. $O$ estudo procura configurar a diferença que poderia demarcar posicionamentos éticos diferenciais perante um mesmo fato de linguagem.

PALAVRAS-CHAVE: Psicanálise; literatura; ética; estética.

"A maneira como o psicanalista descobre porque uma pessoa ri, é análoga a uma investigação estética".

Ludwing Wittgenstein

"Há uma relação do belo com o desejo".

Jacques Lacan

$\sqrt{4}$

m carta a seu amigo Arnold Zweig, de 2 de abril de 1937, quase no final da sua vida, encontramos - em relação à teoria de Thomas Looney, aquela que propunha que W. Shakespeare não seria o autor de Stratford mas o duque de Oxford, Edward de Vere - as seguintes linhas de Sigmund Freud:

* Psicanalista. Universidade Federal de Santa Catarina. Doutorando em Literatura. 
VILLARI, Rafael Andrés. Da estética à (est)ética.

"Ele parece não ter nada que justifique sua afirmação, enquanto Oxford tem quase tudo. Para mim, é inteiramente inconcebível que Shakespeare obtivesse tudo de segunda mão - a neurose de Hamlet, a loucura de Lear, a ousadia de Macheth e o caráter de Lady Macbeth, o ciúme de Otelo etc. Quase me irrita que você defenda essa idéia". (Freud apud Bloom, 1995: 360).

S. Freud acreditava que W. Shakespeare seria uma ficção, tratar-seia de um heterônimo do duque de Oxford. Podemos interpretar este fato de diferentes maneiras. Uma das mais instigantes é a proposta pelo poderoso e polêmico crítico literário - e respeitado estudioso do Shakespearismo - Harold Bloom. Em seu texto, Freud: uma leitura Shakespeariana ${ }^{1}$, o autor assimila a relação entre $\mathrm{S}$. Freud e W. Shakespeare à angústia de influência ${ }^{2}$ que sofreriam os criadores, em relação aos precursores, "Todo texto - segundo o crítico americano - é uma leitura de outro texto, cuja finalidade é livrar-se da influência deste último, fingindo ser, ao mesmo tempo, o ponto de origem. $\mathrm{O}$ que Bloom denomina 'angústia de influência, e a sensação paralisadora ${ }^{3}$ que todo poeta tem do precursor $[\ldots]^{\prime 4}$ ". (Goldemberg, 1997: 51) Nessa trilha, encontramos no discurso - lido por sua filha Anna - por ocasião do recebimento do prêmio "Goethe", palavras que parecem confirmar a idéia proposta por H. Bloom. S. Freud comenta:

"Nos resulta a todos evidentemente desagradable ${ }^{5}$ no saber todavía quién escribió realmente las comedias, las tragedias y los sonetos de Shakespea-

1 BLOOM, H. (1985) "Freud: uma leitura Shakespeariana". In: O cânone ocidental. Os livros e escolha do tempo. Rio de Janeiro: Objetiva, 3. ed. p. 357-379.

2 Ver BLOOM, H. (1991) A angústia de influência. São Paulo: Imago. Trad. A Nestrovski.

3 O itálico é nosso.

- BLOOM, H. (1991) A angústia de influência. São Paulo: Imago. Trad. A Nestrovski.

5 A opção pela citação em espanhol dos trabalhos de Sigmund Freud, corresponde ao fato de serem, os textos nesta língua, uma tradução direta do original $\mathrm{em}$ alemão; sendo que a maior parte dos textos em português são traduções da Standard Edition - versão inglesa - dirigida por James Strachey. Ou seja, a versão em português corresponde à tradução de uma primeira tradução para o inglês. Além disto, conhecemos as críticas que recaem sobre o texto em inglês, texto base da edição brasileira. Preferimos então, citar o texto 
Rev. $A N P() L L$, n. 6/7, p. 89-99, jan./dez. 1999

re: si en realidad fue el inculto hijo del pequeño burgués de Stratford, que alcanzó en Londres una modesta posición como actor, o si, en efecto, no fue más bien un aristócrata de alta alcurnia y de fina cultura, apasionadamente disoluto y más o menos degradado: Edward de Vere, decimoséptimo Earl de Oxford, lord gran chambelán hereditario de Inglaterra" 6 .

\section{e prossegue desta forma aproximando-nos do problema da angústia de influência levantada pelo crítico:}

"¿Cómo se justifica, empero, esta necesidad de conocer las circunstancias de la existencia de un hombre, una vez que sus obras han adquirido tal importancia para nosotros? Dícese, por lo general, que es la necesidad de acercárnoslo también humanamente. Así sea: trataríase entonces del anhelo de crear con tales seres vínculos afectivos que permitan equipararlos a los padres, maestros, modelos que hemos conocido personalmente o cuya influencia ya hemos experimentado, en la esperanza de que sus personalidades han de ser tan grandiosas y admirables como las obras que nos han legado". (Freud, 1973: 3071)?.

Para H. Bloom, o precursor, o centro do cânone ocidental é indiscutivelmente William Shakespeare. Referindo-se à presença de elementos shakespearianos no texto de $\mathrm{S}$. Freud chega a afirmar - e é isto o que nos interessa - que, "a menos que se seja um religioso freudiano, essa é a antiga história da influência literária e suas angústias. Shakespeare é o inventor da psicanálise; Freud, seu codificador" ". (Bloom, 1995: 361).

em espanhol - na versão de Luis Lopez Ballesteros y Torres - colocando em nota de rodapé, na primeira vez em que é citado, o título em alemão, e a referência da edição brasileira. Sobre a questâo da tradução das obras de S. Freud para o português, ver os artigos de Marilene Carone e Paulo César Souza reunidos em: Souza, P. C. (org.). (1989) Sigmund Freud \& o gabinete do Dr. Lacan. São Paulo: Brasilense, p. 15j-190.

6 Esta idéia é recorrente na obra de S. Freud, a encontramos também em: Freud, Sigmund. (1973) La interpretación de los sueños.. In: Obras Completas. Madrid: Biblioteca Nueva, V. I, p. 510., (1973) Autobiografia. In: Obras Completas. Madrid: Biblioteca Nueva, v. II, p. 2794. e em (1973) Compendio del Psicoanálisis. In: Obras Completas. Madrid: Biblioteca Nueva, v. III, p. 3409.

7 Este texto não foi encontrado na Edição Standard Brasileira.

8 O itálico é nosso. 
Uma afirmação destas, para alguém que algum tempo vem estudando as relações entre a Psicanálise e a Literatura ${ }^{9}$, assinala novas vias de análise para este problema. $\mathrm{O}$ texto de $\mathrm{H}$. Bloom reaviva a questão da proximidade entre a Literatura e a Psicanálise, quando propõe S. Freud como o codificador do texto de Shakespeare. Parece pairar nesta proposta o menosprezo pela figura de S. Freud ${ }^{10}$. Mas, sem precipitar-nos, lembremos que codificar remete na sua terceira acepção a "transformar em códice; reunir, coligir, compilar: codificar documentos históricos" ${ }^{11}$. Por outro lado, códice na sua segunda acepção implica "registro ou compilação de manuscritos, documentos históricos, ou leis; código antigo" " 12 . Permitimonos o recurso ao etimologismo, estratégia que "[...] consiste em remergulhar a palavra em sua fonte, para devolvê-la rejuvenescida, rica de sentidos e parentescos perdidos ou esquecidos". (Perrone-Moisés in Barthes, 1992:71), para com isto, deslocar a aparente intenção de crítico.

Vejamos mais de perto o lugar que H. Bloom outorga à obra de Shakespeare. Sabemos que a instala, no centro do cânone ocidental, como texto inaugural de uma forma narrativa, presente até hoje. Mas o que nos interessa neste momento é a influência que poderia ter exercido sobre a obra de S. Freud. Todos os que freqüentamos o texto freudiano, sabemos desta e de outras influências reconhecidas e sofridas por S. Freud, na medida em que a psicanálise é uma ciência feita de outras ciências. Pensamos na necessária vampirização deste tipo de construção, quiçá sua forma palimpséstica. O interessante, e aparentemente menos discutido, da proposta de H. Bloom reside na idéia de que W. Shakespeare teria inaugurado,

9 Ver o nosso trabalho, VILLARI, Rafael Andrés. Relações Possíveis e Impossíveis entre a Psicanálise e a Literatura. In: Ernesto Sábato e a Melancolia. Florianópolis, 1997. 124 p. Dissertação (Mestrado em Literatura - Curso de Pós-Graduação em Literatura, Universidade Federal de Santa Catarina, p. 7-19).

10 Assinalemos a marcada ambigüidade que perıneia o texto de $\mathrm{H}$. Bloom em relação a S. Freud e sua obra.

11 Buarque de Holanda Ferreira Aurélio, Dicionário Electrônico Aurélio. Versão 2.0. Rio de Janeiro: Nova Fronteira.

12 Buarque de Holanda Ferreira Aurélio, Dicionário Electrônico Aurélio. Versão 2.0. Rio de Janeiro: Nova Fronteira. 
Rev. $A N P() L L$, n. 6/7, p. 89-99, jan./dez. 1999

com sua narrativa, a subjetividade ocidental. $\Lambda$ aposta do autor é nesse sentido. Seus argumentos, consistentes. Nada mais, nada menos, "hoje, a literatura, a filosofia e o pensamento estão shakespearizados. $\Lambda$ mente dele é o horizonte além do qual, atualmente, não vemos". (Emerson apud Bloom, 1995: 378). Nas obras de W. Shakespeare encontramos, conforme H. Bloom, pela primeira vez na literatura ocidental, particularidades subjetivas não encontradas anteriormente; referimo-nos, por exemplo, à reversibilidade dos personagens, essa situação quase que de independência dos mesmos, a ambigüidade. Mas fundamentalmente, a questão do diálogo interior. Não se conhece outro antecedente neste sentido: os personagens submersos no conflito interior, dialogando consigo mesmos, ou seja, o aparecimento do monólogo interior. Como afirma H. Bloom, o homem de Stratford cria e demonstra a subjetividade ocidental: Hamlet, MacBeth, Otelo, Lear, são alguns dos representantes desta nova subjetividade. Quando afirma que S. Freud é um codificador - e Shakespeare o inventor da psicanálise - parece-nos que $\mathrm{H}$. Bloom confunde a criação e representação de um tipo de subjetividade com, justamente, sua codificação. Lembremos o anteriormente dito sobre $o$ ato do codificador: transformar em códice. $\Lambda$ psicanálise poderia assimilar-se ao códice quando pensamos que se trata do registro ou compilação de manuscritos, documentos históricos, ou leis. No sentido que assinala Humberto Eco, "[...] os livros falam sempre de outros livros e toda história conta uma história já contada” (Eco: 20).

Quando nos referimos ao campo da Literatura - concebida como campo epistêmico - assinalamos que o recurso ao conhecimento esta dado pelo viés da estética. $\Lambda$ literatura enquanto campo para o conhecimento opera com esse aspecto tão sutil, fugidio e problemático. Nos aproximamos do conceito de estética pensando que trata-se de um efeito particular, o qual - em princípio - parece remeter ao belo, ou a concepção particular de beleza que o sujeito partilha com outros. Na raiz do significante encontramos o aisthanesthai grego que poderia significar sentir. Neste textoante a necessidade de uma definição provisória que oriente - recortamos o 
VILLARI, Rafael Andrés. Da estética à (est)ética.

sentido e a complexidade do assunto pensando o estético como o campo de estudo do belo - enquanto produção subjetiva - na natureza e na arte. A partir desta via de aproximação podemos ampliar a definição como a "ciencia de la cualidades de nuestra sensibilidad" (Freud, 1973: 2483) ${ }^{13}$. O belo aparece como disparador dessa sensação que remetemos ao par prazer/gozo, assinalado por R. Barthes, "prazer/gozo: terminologicamente isto ainda vacila, tropeço, confundo-me. De toda maneira, haverá sempre uma margem de indecisão; a distinção não será origem de classificações seguras, o paradigma rangerá, o sentido será precário, revogável, reversível, o discurso será incompleto". (Barthes, 1993: 8). Assim:

"A conclusão genérica do ensaísta (do escritor) é de ordem estética e resgata a força tenaz da forma que continua dizendo-nos algo, pedindo uma resposta, colocando-nos a enigmática pergunta: '¿La música, los estados de felicidad, la mitología, las caras trabajadas por el tiempo, ciertos crepusculos y cierlos lugares, quierem decirnos algo, o algo dijeron que no hubiéramos debido perder, o estan por decir algo; esta inminencia de uma revelación ${ }^{1+}$, que no se produce, es, quizá, el hecho estético?" ". (Arrigucci Jr.., 1987: 234-235).

A literatura privilegia esta forma de relação com o conhecimento, a estética como caminho não somente de aproximação, mas também como possibilidade real de intervenção na subjetividade: não somos mais os mesmos após alguma música, alguma pintura, algum livro,

"Albrecht Wellmer chamou-me a atenção para como a experiência estéti-
ca [...] pode ter o alcance de sua significação alterado: tão logo tal expe-
riência vem iluminar uma situação de história pessoal e se relaciona a
problemas de vivência, transforma-se em um jogo de linguagem que não
é mais o do crítico de arte. Neste momento, a experiência estética não só
renova a interpretação de nossas carências, à luz das quais percebemos o

13 Das Unheimliche. Freud, S. (1990) A estranheza. In: Edição Standard Brasileira das Obras Psicológicas Completas de Sigmund Freud. 3. ed. Rio de Janeiro: Imago. vol. XVII, 1990.

14 O itálico é nosso. 
Rev. $A N P() L L$, n. 6/7, p. 89-99, jan./dez. 1999

mundo - ela permeia tanto nossas significações cognitivas, quanto nossas expectativas morais, mudando a maneira pela qual estes momentos se referem um ao outro". (Habermas, 1983: 90).

$\Lambda$ revolução freudiana, e isto escapa a $\mathrm{H}$. Bloom, reside em avançar além da estética. Ultrapassar essa fronteira significa dar aos efeitos de linguagem outro relevo, sem descuidar a conseqüência subjetiva do fato estético. S. Freud vai além da estética quando "[...] inventa uma relação inédita com a linguagem, que lhe permite fazer da estética uma ética" (Goldemberg, 1997: 53). H. Bloom é um estudioso das influências literárias e diz se sentir "muito sozinho defendendo a autonomia do estético" (1995: 19). Vemos que, - em relação as formações do inconsciente - há outro viés além do estético, o ético.

Lembremos o recurso ao ato falho nos textos literários: esses enganos propositais que nos dizem de alguma verdade 'oculta' nas peças ${ }^{15}$. S. Freud afirma:

"Más de una vez se han servido diversos poetas de la equivocación oral y de otros actos fallidos como medios de representación poética. Este solo hecho basta para probarnos que el poeta considera el acto fallido (por ejemplo,

15 Como diz S. Freud: "O. Rank ha descubierto en Shakespeare un ejemplo, aún más impresionante, $|\ldots|$. Hállase este ejemplo en El mercader de Venecia y en la célebre escena en la que el feliz amante debe escoger entre tres cofrecillos que Porcia le presenta. Lo mejor será copiar la breve exposición que Rank hace de este pasaje: Otro ejemplo de equivocación oral delicadamente motivado, utilizado con gran maestría técnica por un poeta y similar al señalado por Freud en el Wallenstein, de Schiller, nos enseña que los poetas conocen muy bien la significación y el mecanismo de esta función fallida, y suponen que también los conoce o los comprenderá el público. Este ejemplo lo hallamos en El mercader de Venecia (acto tercero, escena segunda), de Shakespeare. Porcia, obligada por la voluntad de su padre a tomar por marido a aquel de sus pretendientes que acierte a escoger una de las tres cajas que le son presentadas, ha tenido hasta el momento la fortuna de que ninguno de aquellos amadores que no le eran gratos acertase en su elección. Por fin, encuentra en Bassanio el hombre a quien entregaría gustosa su amor, y entonces teme que salga también vencido en la prueba. Quisiera decirle que, aun sucediendo así, puede estar seguro de que ella le seguirá amando, pero su juramento se lo impide. En este conflicto interior le hace decir el poeta a su afortunado pretendiente: 'Quisiera reteneros aquí un mes o dos antes de que aventurarais la elección de que dependo. Podría indicaros cómo escoger con acierto. Pero si así lo hiciera sería perjura, y no lo seré jamás. Por otra parte, podéis no obtenerme, y si esto sucede, haríais arrepentirme, lo cual sería un pecado, de no haber 
VILLARI, Rafael Andrés. Da estética à (est)ética.

la equivocación oral) como algo pleno de sentido, pues lo hace producirse intencionadamente, dado que no podemos pensar que se ha equivocado al escribir su obra y deja luego que su equivocación en la escritura subsista, convirtiéndose en una equivocación oral de su personaje". (1973: $2138)^{16}$.

$\mathrm{O}$ efeito é fundamentalmente estético, ante este recurso de linguagem - o mesmo - S. Freud propõem uma ética de onde se produz uma nova relação com este fato de linguagem. Ante um ato falho, ou um chiste:

"[...] o prazer estético estará a serviço da censura. Rimos juntos para esquecermos melhor o que ali se disse, para que tudo continue igual na economia libidinal da neurose, evitando-se arranhões no narcisismo. Mas se isso nem sempre é possível na vida quotidiana, na psicanálise é um dever que assim não seja. $O$ caráter produtivo do erro não é, portanto, só estético, mas também ético ${ }^{17}$ ". (Goldemberg, 1997: 53)

Quando J. Lacan discorre sobre a ética que nos concerne como analistas, parece-nos que aborda o problema da ética de uma forma mais abrangente. Se bem o seminário titula-se $A$ ética da psicanálise, onde de alguma maneira pareceria demarcar o alcance de alguma ética particular à psicanálise, a questão é mais geral e ambiciosa. Avançando na lógica do

faltado a mi juramento. iMal hayan vuestros ojos! Se han hecho dueños de mi ser y lo han dividido en dos partes, de las cuales la una es vuestra y la otra es vuestra, digo mía; mas siendo mía, es vuestra, y así soy toda vuestra'. Así, pues, aquello que Porcia quería tan sólo indicar ligeramente a Bassanio, por ser algo que en realidad debía callar en absoluto, esto es, que ya antes de la prueba le amaba y era toda suya, deja el poeta, con admirable sensibilidad psicológica, que aparezca claramente en la equivocación, y por medio de este artificio consigue calmar tanto la insoportable incertidumbre del amante como la similar tensión del público sobre el resultado de la elección. Observamos también con qué sutileza acaba Porcia por conciliar las dos manifestaciones contenidas en su equivocación y por suprimir la contradicción que existe entre ellas, dando, sin embargo, libre curso a la expresión de su promesa: 'Mas siendo mía, es vuestra, y así soy toda vuestra' ". (Freud, 1973: 2139-2140).

16 Vorlesungem zur Einführung in die Psychoanalyse. Freud, S. (1990) Conferências Introdutórias sobre Psicanálise. In: Ediçāo Standard Brasileira das Obras Psicológicas Completas de Sigmund Freud. 3. ed. Rio de Janeiro: Imago. Vol. XV-XVI, 1990.

17 O itálico é nosso. 
Rev. $A N P(L L$, n. 6/7, p. 89-99, jan./dez. 1999

seminário vemos como desenvolve-se a análise do problema ético com a incorporação do discurso psicanalítico na cultura, quer dizer, pela inserção desse "modo inédito de resposta à palavra do outro" (Goldemberg, 1997: 54), iluminando alguns aspectos do problema.

$\Lambda$ introdução dessa resposta particular à palavra do outro, é o tour de force, onde a psicanálise desprende-se da Literatura. É o ponto onde avançando além da proposta de $\mathrm{H}$. Bloom -, S. Freud desprende-se de W. Shakespeare. Concebendo, a partir dos mesmos efeitos de linguagem, outras conseqüências. Esta novidade introduzida responde a uma ética exigência - particular, fazendo de S. Freud um precursor. Quebrando a homogeneidade do campo estético onde estariam - conforme H. Bloom tanto W. Shakespeare como S. Freud. Tratar-se-ia de terrenos diferenciados.

Lembremos que J. Lacan diz que "a ética consiste essencialemente[...] num juízo sobre nossa ação" (Lacan, 1988: 373). Ao mesmo tempo, afirma que há uma relação entre essa "[...] ação com o desejo que a habita" (Lacan, 1988: 376). Assim, quando de ética se trata, devemos remitir-nos ao desejo. Desta forma, a introdução do discurso analítico na cultura propicia colocar o desejo no centro da questão:

"[...] é por sabermos, melhor do que aqueles que os precederam, reconhecer a natureza do desejo que está no âmago dessa experiência, que uma revisão ética é possível, que um juízo ético é possível, o qual representa essa questão com seu valor de Juízo final.

'Agiste conforme o desejo que te habita?'

Isto não é uma questão fácil de sustentar. Pretendo que ela jamais foi colocada de maneira pura em outro lugar, e que não pode ser colocada senão no contexto analítico". (Lacan, 1988: 376-377)

Esta ética constrói o próprio campo, na medida em que ela orienta e demarca a experiência da psicanálise. No centro encontramos o desejo do analista, o desejo de Freud. De alguma forma trata-se de ir além do efeito 
VILLARI, Rafael Andrés. Da estética à (est)ética.

estético, fazendo deste ato um ato (est)ético ${ }^{18}$. Como dizemos - e aqui nos encontramos com o título deste trabalho - ir de uma estética à uma (est)ética. Este é o ponto invariável ao redor do qual giram as possibilidades da constituição do campo. Temos assim, uma ética que responde de forma particular a um desejo determinado.

Neste sentido se S. Freud foi além de Shakespeare, isto não significa que a ética psicanalítica vai além da estética. Retomemos o significante est-ética. Na estética, uma ética. Isto quer dizer que, no centro do campo estético, encontramos outro desejo - diferente daquele do analista - orientando a produção. Se a estética responde a um ética, qual o desejo que a orienta? Perante qual desejo não deve-se ceder neste terreno? Já que da mesma forma em que a psicanálise diferencia-se da literatura através de uma distinção na sua ética diferencial, devemo-nos questionar pela particularidade ética que veicula a estética. Não retroceder ante o estético e seus efeitos, significa perguntar-se pela singularidade do desejo que a comanda. Não avançaremos aqui sobre esse terreno, porém propomos - para um futuro momento - investigar essa via através da noção de texto e escritura na obra de Roland Barthes.

\begin{abstract}
The text seeks - leaving of Sigmund Freud's doubt on William Shakespeare's true origin and of the North American critic's formulation Harold Bloom on the influence anguish - to mark the existent distinction between the aesthetic effect and the ethical consequence of the formations of the Freud's unconscious. The study tries to configure the difference that could demarcate ethical positionings you differentiate before a same language fact.
\end{abstract}

KEYWORDS: Psychoanalysis; literature; ethics; aesthetics.

18 Esta partição do significante a encontramos em Oliveira Ramos, T. R. Memórias. Uma oportunidade poética. Tese de doutorado. Rio de Janeiro. 1990 PUC. p. 21. 
Rev. ANPOLL, n. 6/7, p. 89-99, jan./dez. 1999

\section{BIBLIOGRAFIA}

ARRIGUCCI Jr., D. (1987) Enigma e Comentário (Epílogo). In: Enigma e Comentário. Ensaios sobre literatura e experiência. São Paulo: Companhia das Letras. p. 227235.

BARTHES, R. (1992) Aula. São Paulo: Cultrix, 6. ed. Trad. Leila Perrone-Moisés. . (1993) O prazer do texto. São Paulo: Perspectiva. Trad. J. Guinsburg

BLOOM, H. (1995) O cânone ocidental. Os livros e escolha do tempo. Rio de Janeiro: Objetiva, 3. ed. Trad. Marcos Santarrita.

ECO, H. Pós-escrito a O nome da rosa. Rio de Janeiro: Nova Fronteira. (Texto xerografado sem data).

FREUD, S. (1973) Prêmio Goethe de 1930. Discurso en la casa de Goethe, em Frankfurt. In: Obras Completas. Madrid: Biblioteca Nueva. v. III, p. 3068-3073. Trad. Luiz Lopez Ballesteros y Torres.

. (1973) Lo siniestro. In: Obras Completas. Madrid: Biblioteca Nueva, v. III, p. 2483-2505. Trad. Luiz Lopez Ballesteros y Torres.

. (1973) Lecciones introductórias al psicoanálisis. In: Obras Completas. Madrid: Biblioteca Nueva, v. II, p. 2123-2413. Trad. Luiz Lopez Ballesteros y Torres.

GOLDEMBERG, R. (1997) Plágio. Sobre o uso crítico da psicanálise (a propósito da desleitura de Freud). In: Correio da APPOA, Psicanálise e Literatura. Escrevendo a Clínica. n. 50, set. p. 48-57.

HABERMAS, J. (1983) Modernidade versus pós-modernidade. In: Arte em revista. São Paulo, n. 7, ago. p. 86-91.

LACAN, J. (1988) O seminário: A ética da psicanálise. Rio de Janeiro: Jorge Zahar Editor. Trad. Antônio Quinet. 